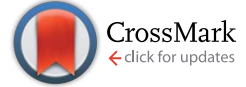

Cite this: RSC Adv., 2016, 6, 65475

Received 4th June 2016

Accepted 5th July 2016

DOI: 10.1039/c6ra14544b

www.rsc.org/advances

\section{A study of $\mathrm{CO}_{2} / \mathrm{CO}$ separation by sub-micron b-oriented MFI membranes}

\author{
D. Korelskiy, ${ }^{*}$ M. Grahn, P. Ye, M. Zhou and J. Hedlund
}

Separation of $\mathrm{CO}_{2}$ and $\mathrm{CO}$ is of great importance for many industrial applications. Today, $\mathrm{CO}_{2}$ is removed from $\mathrm{CO}$ mainly by adsorption or physical or chemical absorption systems that are energy-intensive and expensive. Membranes are listed among the most promising sustainable and energy-efficient alternatives for $\mathrm{CO}_{2}$ separation. Here, we study $\mathrm{CO}_{2} / \mathrm{CO}$ separation by novel sub-micron $b$-oriented MFI zeolite membranes in a temperature range of $258-303 \mathrm{~K}$ and at a feed pressure of 9 bar. Under all experimental conditions studied, the membranes were $\mathrm{CO}_{2}$-selective and displayed high $\mathrm{CO}_{2}$ permeance ranging from 17000 to $23000 \mathrm{gpu}$. With decreasing temperature, the $\mathrm{CO}_{2} / \mathrm{CO}$ selectivity was increasing, reaching a maximum of 26 at $258 \mathrm{~K}$. We also developed a mathematical model to describe the membrane process, and it indicated that the membrane separation performance was a result of selective adsorption of $\mathrm{CO}_{2}$ on the polar zeolite. The heat of adsorption of $\mathrm{CO}_{2}$ on the zeolite is more negative due to the high quadrupole moment and polarisability of the molecule as compared to $\mathrm{CO}$. At the same time, diffusional coupling (correlation effects) at high adsorbed loadings was found to favour the overall $\mathrm{CO}_{2} / \mathrm{CO}$ selectivity of the membranes by reducing the diffusivity of the lighter CO molecule in the ca. $0.55 \mathrm{~nm}$ pores in the zeolite. The model also indicated that the separation performance was limited by the mass transfer resistance in the support and concentration polarisation on the feed side of the membrane.

\section{Introduction}

$\mathrm{CO}$ is used for manufacture of a wide range of valuable chemicals, such as oxo-alcohols, phosgene (intermediate for polyurethane), methanol, acetic acid or various liquid hydrocarbon fuels via the Fischer-Tropsch process. CO itself is often produced by gasification (partial oxidation) of carboncontaining materials, e.g. coal, biomass, etc., or steam reforming of natural gas. In addition to $\mathrm{CO}$, the produced gas mixture, referred to as synthesis gas, contains $\mathrm{H}_{2}, \mathrm{CO}_{2}$ and minor impurities, e.g. $\mathrm{N}_{2}, \mathrm{H}_{2} \mathrm{O}, \mathrm{H}_{2} \mathrm{~S}$, etc. To utilise for the synthesis of chemicals, $\mathrm{CO}$ usually has to be purified, mainly from $\mathrm{CO}_{2}$. For instance, the gas used for oxo-synthesis should contain $\leq 0.5 \%$ of $\mathrm{CO}_{2}{ }^{1}$ Separation of $\mathrm{CO}$ and $\mathrm{CO}_{2}$ is, however, challenging since the properties of the two gases are rather similar. Most of the currently available $\mathrm{CO}_{2}$ separation methods rely on adsorption or absorption, e.g. pressure swing adsorption or amine scrubbing. ${ }^{2}$ Despite certain advantages, the sorptionbased separation systems are cumbersome, rather energyintensive and require large capital investments. ${ }^{3}$ Moreover, the absorbents used today are often corrosive and may release hazardous substances into the environment.

Membranes are an appealing alternative to many common separation technologies, including adsorption, absorption and

Chemical Technology, Luleå University of Technology, SE-97187 Luleå, Sweden. E-mail: danil.korelskiy@ltu.se cryogenic distillation. High efficiency, sustainability and low energy demand are defining characteristics of membrane-based separation methods. Moreover, membrane separation processes are simple and continuous, requiring a minimum of process equipment. For instance, we have recently demonstrated $^{4}$ that only one module housing $10 \mathrm{~m}^{2}$ of membrane area could replace an entire amine scrubbing system for separation of 300 ton $\mathrm{CO}_{2}$ per day from synthesis gas. It is worth pointing out that membranes have been listed among the most promising $\mathrm{CO}_{2}$ separation and capture technologies. ${ }^{3}$ The $\mathrm{CO}_{2}-$ selective membranes currently available on the market are polymeric membranes. These membranes can be manufactured in large quantities at fairly low costs. At the same time, large membrane areas are a necessity for a given separation task because the membranes have low permeability, often coupled with a fairly poor selectivity. For example, Polaris ${ }^{\mathrm{TM}}$ membranes have a $\mathrm{CO}_{2}$ permeance of 100-300 gpu (1 gpu $=3.35 \times 10^{-10}$ mol s${ }^{-1} \mathrm{~m}^{-2} \mathrm{~Pa}^{-1}$ ) and a $\mathrm{CO}_{2} / \mathrm{CO}$ selectivity of $10-20$ at a temperature ranging from 268 to $298 \mathrm{~K} .{ }^{5}$ Even state-of-the-art $\mathrm{CO}_{2}$-selective polymeric membranes display a $\mathrm{CO}_{2}$ permeance of at most 1000 gpu. ${ }^{6}$ In addition, $\mathrm{CO}_{2}$ has a detrimental effect on the membrane stability, especially at high concentrations (pressures), reducing the membrane performance and lifespan. ${ }^{3}$

Among inorganic $\mathrm{CO}_{2}$-selective membranes, zeolite membranes are particularly attractive. ${ }^{7}$ These membranes have a well-defined pore system with pores ranging from 0.3 to 1.3 
$\mathrm{nm}$ in size. ${ }^{8}$ Hence, zeolite membranes are microporous membranes. Due to the microporous structure, the separation mechanism by zeolite membranes can rely on molecular sieving (size exclusion), differences in adsorption or differences in diffusion between the separated components. Being highly porous and thin, zeolite membranes can exhibit much higher fluxes than polymeric membranes. ${ }^{9}$ Currently, zeolite films as thin as $100 \mathrm{~nm}$ can be prepared, displaying a high $n$-butane permeance up to $c a .4000$ gpu. ${ }^{10}$ As a consequence, much lower membrane areas would suffice for a given separation task. In addition, the chemical and thermal stability of zeolite membranes is vastly superior to that of polymeric membranes. ${ }^{\mathbf{1 1}}$

In spite of the great interest in separation of the main components of synthesis gas, i.e. $\mathrm{CO}, \mathrm{H}_{2}$ and $\mathrm{CO}_{2}$, the number of research reports on zeolite membranes for this separation is small. ${ }^{7}$ In particular, $\mathrm{CO}_{2} / \mathrm{CO}$ membrane separation has scarcely been studied. Our research group ${ }^{13}$ has previously evaluated a sub-micron randomly oriented highly siliceous MFI zeolite membrane for the separation of an equimolar mixture of $\mathrm{CO}_{2}, \mathrm{H}_{2}$ and $\mathrm{CO}$. The membrane was $\mathrm{CO}_{2}$-selective with a high $\mathrm{CO}_{2}$ permeance up to $c a .24000 \mathrm{gpu}$. At a temperature of $277 \mathrm{~K}$ and a feed pressure of 9 bar, a $\mathrm{CO}_{2} / \mathrm{CO}$ membrane selectivity of ca. 10 was reported. The highly siliceous MFI zeolite (also referred to as siliceous ZSM- 5 with a unit cell represented by the
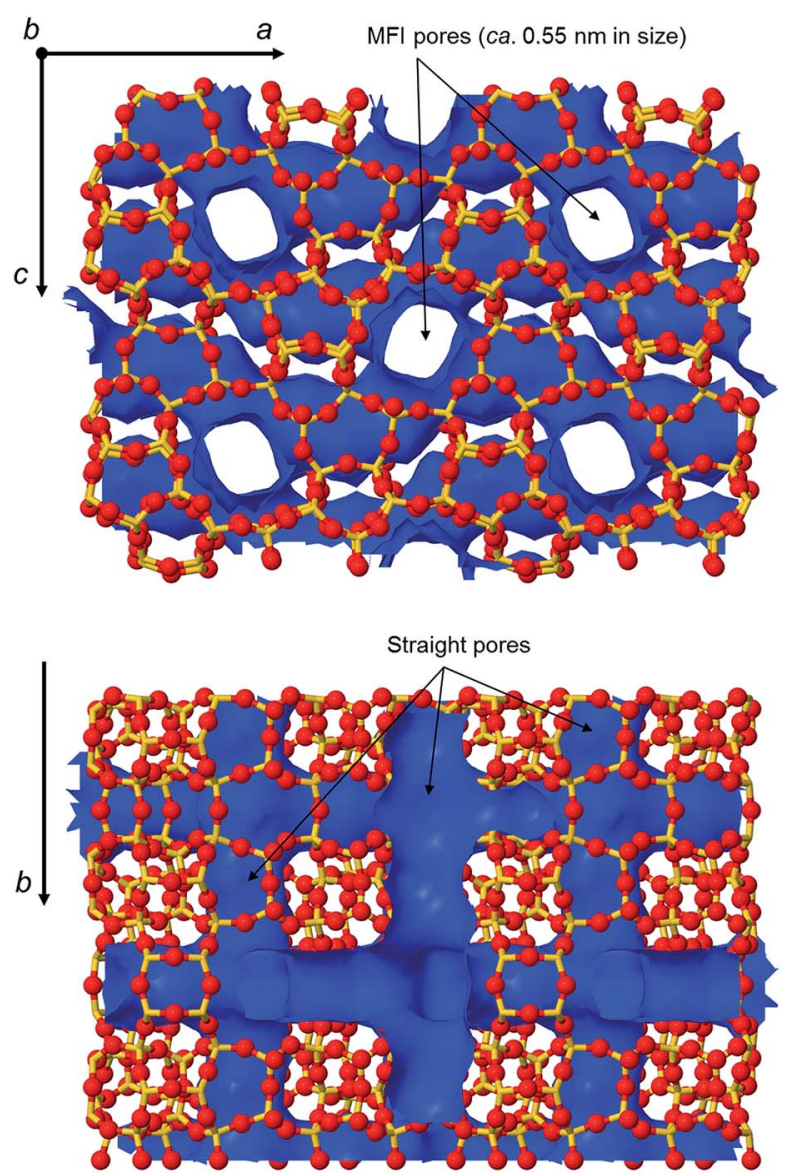

Fig. 1 Schematic representation of the MFI zeolite crystal structure ${ }^{12}$ (the pore surface is in blue). general chemical formula $\left.\left[\mathrm{Si}_{96} \mathrm{O}_{192}\right]-\mathrm{MFI}\right)^{\mathbf{1 4}}$ has a threedimensional pore structure comprised of two types of intersecting pores, viz. tortuous and straight with an average pore diameter of $c a .0 .55 \mathrm{~nm} .{ }^{12}$ The tortuous (sinusoidal) pores are running in the $a$-direction, whereas the straight pores are running in the $b$-direction, see Fig. 1 . Molecules can also diffuse in the $c$-direction by alternating between the straight and sinusoidal pores. However, the diffusion in the $c$-direction is significantly slower than in the $a$ - and $b$-directions. ${ }^{\mathbf{1 5 , 1 6}}$ It has been shown ${ }^{14,17}$ that $b$-oriented MFI films may allow for somewhat faster transport of molecules, especially bulky molecules (e.g. xylenes) since the straight pores will be running along the film thickness. The $b$-orientation has therefore been considered preferable.

Recently, we $\mathrm{e}^{\mathbf{1 8}}$ have developed a sub-micron $b$-oriented MFI membrane employing a fluoride route (neutral $\mathrm{pH}$ ) for the synthesis. The developed membranes displayed high $\mathrm{CO}_{2} / \mathrm{H}_{2}$ and $\mathrm{CO}_{2} / \mathrm{CO}$ selectivities up to $\mathrm{ca} .110$ and 20, respectively. Here, we extend our previous work on $\mathrm{CO}_{2} / \mathrm{CO}$ separation using submicron $b$-oriented MFI membranes by developing a model to elucidate the separation mechanism and describe the effect of the support and concentration polarisation on the membrane separation performance. In addition, the morphology of the membranes, especially the grain boundaries and grain size, was carefully studied by SEM. Permporometry data were used to estimate the width of the open grain boundaries and the grain size, and the findings were compared with the SEM data.

\section{Experimental}

\section{Membrane synthesis}

Sub-micron ( $c a .0 .5 \mu \mathrm{m}) b$-oriented MFI zeolite membranes were prepared as described in detail in our previous work. ${ }^{18}$ The membranes were supported on a commercial graded $\alpha$-alumina disc (Fraunhofer IKTS, Germany) with a diameter of $25 \mathrm{~mm}$. A brief summary of the membrane preparation procedure is given below. In the first step, the supports were seeded with plateshaped MFI crystals with a size of $500 \times 450 \times 200 \mathrm{~nm}$. The seed crystals were synthesised from a mixture containing tetraethyl orthosilicate (TEOS), tetrapropylammonium hydroxide (TPAOH) and water with a respective molar ratio of $1: 0.2: 100$. The mixture was kept at $403 \mathrm{~K}$ for $9 \mathrm{~h}$. In the second step, zeolite films were grown on the seeded supports by hydrothermal synthesis at $373 \mathrm{~K}$ for $48 \mathrm{~h}$ using a synthesis mixture with a molar composition of $\mathrm{SiO}_{2}: 0.12 \mathrm{TPAOH}: 60 \mathrm{H}_{2} \mathrm{O}: 0.12 \mathrm{HF}$. After the synthesis, the membranes were rinsed with a $0.2 \mathrm{M}$ ammonia solution and dried at $323 \mathrm{~K}$ overnight. The following day, the membranes were calcined at $773 \mathrm{~K}$ for $6 \mathrm{~h}$ at a heating rate of $0.2 \mathrm{~K} \mathrm{~min}^{-1}$ and a cooling rate of $0.3 \mathrm{~K} \mathrm{~min}^{-1}$.

\section{Membrane characterisation}

The morphology of the membranes was characterised by Scanning Electron Microscopy (SEM) using a Magellan 400 SEM (the FEI Company, The Netherlands). Cross-sections of the membranes were obtained by fracturing the membranes with 
a pair of cutting pliers. No conductive coating was applied to the samples.

The quality of the membranes in terms of defects was evaluated by $n$-hexane/helium permporometry ${ }^{\mathbf{1 9}}$ as described in detail in our earlier work $\mathbf{k}^{\mathbf{2 0}}$ and in brief here. The membranes were mounted in a stainless steel cell using graphite gaskets (Eriks, The Netherlands) for sealing. In order to remove any adsorbed compounds, the membranes were heated to $573 \mathrm{~K}$ at a heating rate of $1 \mathrm{~K} \mathrm{~min}^{-1}$ and kept at this temperature for $6 \mathrm{~h}$ in a flow of pure helium (99.999\%, AGA). The permporometry experiment was performed at a temperature of $323 \mathrm{~K}$, a total feed pressure of 2 bar and a total permeate pressure of 1 bar. The relative pressure of $n$-hexane (99\%, Alfa Aesar) in the feed was increased in a step-wise manner from 0 to $c a$. 0.4. At each relative pressure, the system was allowed to equilibrate. In order to remove $n$-hexane from the permeate stream, a condenser kept at $233 \mathrm{~K}$ followed by a column packed with activated carbon were employed. A soap bubble flow meter was used to measure the $n$-hexane-free permeate volumetric flow rate. For each $n$-hexane relative pressure, a defect width was calculated by either the Horvàth-Kawazoe equation (micropore-range defects) or the Kelvin equation complemented by the Harkins-Jura equation accounting for the thickness of the adsorbed layer (mesopore-range defects). For each defect interval, the average defect width was then calculated. Based on the average defect width, the average helium diffusivity in each defect interval was estimated using the gas-translational model. Knowing the diffusivity, the helium molar flux was further calculated from Fick's law. The area of defects was estimated as the ratio between helium molar flow and flux through the defects in that particular interval. In the final step, the relative area of defects was calculated by dividing the area of defects with the total membrane area. More details about the evaluation procedure of the permporometry data can be found in our previous work. ${ }^{20}$

In order to identify the type of defects detected by permporometry, a geometrical model of the membrane microstructure was used. It is worth noting that this model is only a rough approximation of the microstructure. In the model, the grains were assumed to have a cuboid habit with a square cross-section with a width of $x$, see Fig. 2. It should be noted that the cuboid habit with a square cross-section was only assumed to simplify the calculation of the grain surface area from the permporometry data. The grain width was assumed to be constant throughout the film thickness. The micropore defects with a weighted arithmetic average width of $d$ were assumed to be evenly distributed between the grains, as shown in Fig. 2 . Therefore, the relative area of micropore defects $a$ can be calculated as

$$
a=\frac{d(x+d+x)}{(x+d)^{2}} .
$$

Since $d$ is much smaller than $x$, eqn (1) can be simplified to

$$
a=\frac{2 d}{x} \text {. }
$$

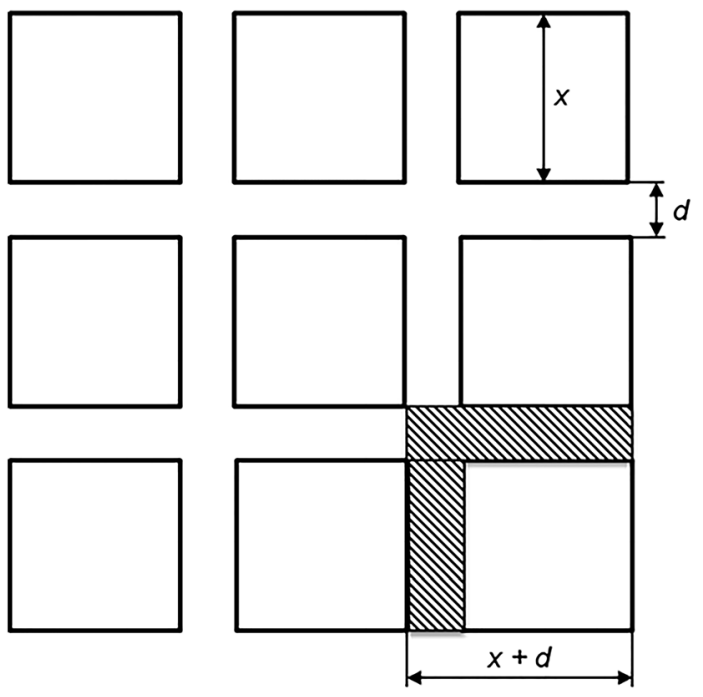

area of defects

$x$ - grain size

$d$ - average micropore defect size

Fig. 2 A geometrical model of the membrane microstructure.

The relative area of micropore defects $a$ can be estimated from permporometry data obtained experimentally. Knowing the relative area, the grain size $x$, and hence the grain surface area, can then easily be calculated using eqn (2).

\section{$\mathrm{CO}_{2} / \mathrm{CO}$ separation experiments}

Mixed-gas separation experiments were carried out using a 50/ $50(\mathrm{v} / \mathrm{v})$ mixture of $\mathrm{CO}_{2}(99.999 \%$, AGA) and $\mathrm{CO}(99.97 \%)$ at a total feed pressure of 9 bar and a total permeate pressure of 1 bar. The membrane was kept in the cell used for the permporometry test. The experiments were carried out at a temperature ranging from 258 to $303 \mathrm{~K}$. Prior to the experiments, the membrane was dried at $573 \mathrm{~K}$ for $6 \mathrm{~h}$ using a stream of pure helium (99.999\%, AGA) to remove any adsorbed species. The volumetric flow rate of the permeate was measured with a drumtype gasmeter (TG Series, Ritter Apparatebau GmbH), and the composition of the permeate was analysed with a mass spectrometer (GAM 400, InProcess Instruments).

The flux of component $i, J_{i}\left(\mathrm{~mol} \mathrm{~s} \mathrm{~s}^{-1} \mathrm{~m}^{-2}\right)$, was estimated from the measured molar flow rate of the corresponding component through the membrane, $F_{i}\left(\mathrm{~mol} \mathrm{~s}^{-1}\right)$ as

$$
J_{i}=F_{i} / A,
$$

where $A$ is the membrane area $\left(\mathrm{m}^{2}\right)$.

The permeance of component $i, \Pi_{i}\left(\mathrm{~mol} \mathrm{~s}^{-1} \mathrm{~m}^{-2} \mathrm{~Pa}^{-1}\right)$, was calculated from the flux of the corresponding component through the membrane as

$$
\Pi_{i}=J_{i} / \Delta P_{i}
$$


where $\Delta P_{i}(\mathrm{~Pa})$ is the partial pressure difference of component $i$ across the membrane. It should be noted that for gas permeation and separation, permeance is normally reported in gpu (gas permeation units), where $1 \mathrm{gpu}$ is equal to $3.35 \times 10^{-10} \mathrm{~mol}$ $\mathrm{s}^{-1} \mathrm{~m}^{-2} \mathrm{~Pa}^{-1}$.

The $\mathrm{CO}_{2} / \mathrm{CO}$ membrane selectivity, $\alpha_{\mathrm{CO}_{2} / \mathrm{CO}}$, was estimated as

$$
\alpha_{\mathrm{CO}_{2} / \mathrm{CO}}=\Pi_{\mathrm{CO}_{2}} / \Pi_{\mathrm{CO}}
$$

\section{Modelling}

For composite membranes, as in this work, high flux may cause both concentration polarisation on the feed side and a pressure drop over the support. These effects may result in a decrease in the performance of the membrane, in terms of both flux and selectivity. ${ }^{21-23}$ To assess to what extent these effects may have influenced the separation performance of the membrane in the present work, a mathematical model was used. The model has been described in detail elsewhere $e^{21,23,24}$ and will only be described briefly below.

The effect of concentration polarisation may be evaluated by determining the concentration polarisation index (CPI) as

$$
\mathrm{CPI}=\exp \left(J_{\mathrm{v}} / k_{\mathrm{c}}\right)+\frac{n_{\mathrm{p}}}{n_{\mathrm{b}}}\left[1-\exp \left(J_{\mathrm{v}} / k_{\mathrm{c}}\right)\right],
$$

where $n_{\mathrm{b}}$ is the mole fraction in the gas bulk, $k_{\mathrm{c}}$ is the mass transfer coefficient, $J_{\mathrm{v}}$ is the volumetric flux and $n_{\mathrm{p}}$ is the mole fraction in the permeate. The mass transfer coefficient may be obtained from mass transfer correlations relating the Sherwood (Sh) number to the Reynolds (Re) and Schmidt (Sc) numbers. Perdana et $a l .{ }^{25}$ have reported a correlation for mass transfer in a Wicke-Kallenbach cell, which is used in the present work.

$$
\mathrm{Sh}=2.83+2.24 \mathrm{Re}^{0.58} \mathrm{Sc}^{0.33}\left(\frac{w}{D_{\mathrm{C}}}\right)^{1.30},
$$

where $w$ is the compartment height, i.e. the thickness of the gas film on the feed side of the membrane and $D_{\mathrm{C}}$ is the diameter of the membrane inside the gaskets, for more details see Perdana et $a .^{25}$ The mass transfer coefficient was finally retrieved from the Sherwood number:

$$
\mathrm{Sh}=\frac{k_{\mathrm{c}} d_{\mathrm{h}}}{D},
$$

where $d_{\mathrm{h}}$ is the hydraulic diameter of the cell and $D$ is the gas phase diffusivity of $\mathrm{CO}_{2}$.

The pressure drop across each layer of the support was determined using procedures described in detail elsewhere. ${ }^{\mathbf{2 1 , 2 6 - 2 8}}$ The transport through the $3 \mathrm{~mm}$ thick base layer with $3 \mu \mathrm{m}$ pores was assumed to occur via viscous flow, whereas transport through the $30 \mu \mathrm{m}$ thick top layer was assumed to occur via a combination of viscous flow and Knudsen diffusion. Effective permeabilities and Knudsen transport coefficients for each of the support layer have been reported in our previous work. $^{21}$

Gas phase diffusivities and viscosities were adjusted to the desired temperature using the $D_{i} \propto T^{3 / 2}$ relationship and Sutherland's equation, ${ }^{29}$ respectively. The viscosities of the mixtures were calculated as molar fraction weighted averages. The ideal adsorbed solution theory (IAST) ${ }^{30}$ was used to estimate adsorbed loadings on the feed side of the membrane during the separation experiment. Saturation loadings, Langmuir affinity coefficients and adsorption enthalpies were taken from the literature. ${ }^{31-34}$

\section{Results and discussion}

\section{Membrane characterisation}

Fig. 3 shows cross-sectional and top-view SEM images of an assynthesised membrane. It is evident that the MFI crystals comprising the film were mainly $b$-oriented. The MFI film was even and continuous, and the crystal length in the $b$-direction, i.e. the film thickness, was ca. $0.5 \mu \mathrm{m}$. The crystals composing the dense part of the film appear to be well-intergrown with
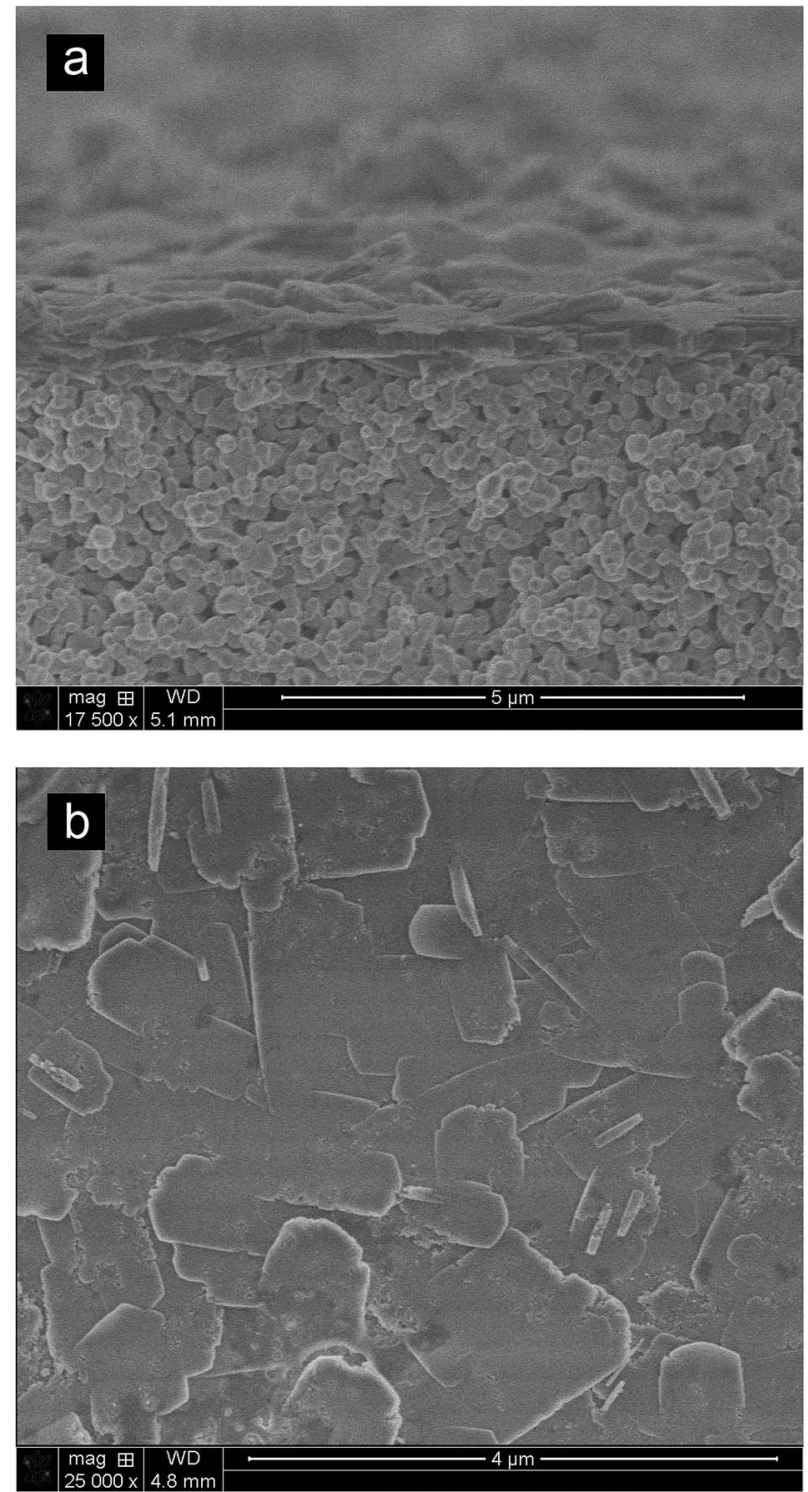

Fig. 3 Cross-sectional (a) and top-view (b) SEM images of an assynthesised membrane. 
a smooth top surface. However, some of the crystals were sticking out of the dense part of the film, displaying a typical rounded boat shape. ${ }^{35}$ The in-plane dimensions of the crystals composing the dense part of the film were found to vary considerably. However, the maximum lengths along the $a$-axis and $c$-axis were $c a$. $0.5 \mu \mathrm{m}$ and $2 \mu \mathrm{m}$, respectively. Defects in the form of cracks and pinholes, which are normally larger than 5 $\mathrm{nm}$, were not detected by SEM. The absence of such defects indicates high quality of the membrane. In Fig. 3a, part of the top layer of the support can also be observed. The grain size of the support is about $150 \mathrm{~nm}$ and the pore size is about $100 \mathrm{~nm}$. No growth of the zeolite into the support, often referred to as invasion, ${ }^{36}$ could be detected, which is desired as the invasion would reduce the permeability of the support. The absence of the invasion can most likely be attributed to the good seeding, resulting in a dense seed layer protecting the support. The $b$ oriented MFI phase comprising as-synthesised membranes was corroborated by X-ray diffraction (XRD), and the data were reported in our previous work. ${ }^{18}$

Table 1 shows the helium permeance through the synthesised membrane measured at each relative pressure of $n$ hexane in the permporometry experiment. The table also shows the relative areas of defects estimated for each defect interval. In the permporometry experiment, the initial measuring point is recorded at a relative pressure of $n$-hexane of 0 . The helium permeance at this point denotes the combined permeance through zeolite pores and defects. For this membrane, the initial helium permeance was high amounting to ca. 20000 $\mathrm{gpu}$, indicating that the zeolite pores are open and permeable. With increasing relative pressure of $n$-hexane, first MFI pores and then defects were blocked by $n$-hexane causing the helium permeance to decrease. The total relative area of defects in the membrane was very small, scarcely above $0.1 \%$ of the total membrane area, indicating a very high quality of the membrane. The few detected defects were essentially only micropore defects, accounting for ca. 99.6\% of all defects. Virtually no mesopore defects were detected by permporometry, which is consistent with the SEM observations.

In our previous work, we showed that the micropore defects detected by permporometry in our randomly oriented high-flux MFI membranes were open grain boundaries. In order to identify whether the detected micropore defects in the $b$ -

Table 1 Permporometry data for the synthesised membrane

\begin{tabular}{llll}
\hline$P / P_{0}$ & $\begin{array}{l}\text { He permeance } \\
(1000 \mathrm{gpu})\end{array}$ & $\begin{array}{l}\text { Defect interval } \\
(\mathrm{nm})\end{array}$ & $\begin{array}{l}\text { Relative area } \\
\text { of defects }\end{array}$ \\
\hline 0 & 20 & - & \\
$2.3 \times 10^{-4}$ & 0.52 & $0.71-0.74$ & $5.9 \times 10^{-2}$ \\
$3.7 \times 10^{-4}$ & 0.35 & $0.74-0.81$ & $4.3 \times 10^{-2}$ \\
$1.1 \times 10^{-3}$ & 0.20 & $0.81-1.05$ & $2.9 \times 10^{-2}$ \\
$1.1 \times 10^{-2}$ & 0.035 & $1.05-1.80$ & $1.1 \times 10^{-3}$ \\
$1.2 \times 10^{-1}$ & 0.022 & $1.80-4.41$ & $9.2 \times 10^{-5}$ \\
$3.7 \times 10^{-1}$ & 0.019 & $>4.41$ & $4.6 \times 10^{-4}$ \\
& & Total & $1.3 \times 10^{-1}$
\end{tabular}

${ }^{a}$ Area of defects per total membrane area. oriented MFI membranes prepared in the present work were as well open grain boundaries, we used a rough geometrical model of the membrane microstructure described in the Experimental. The average width of micropore defects $d$ was estimated from the permporometry data as a weighted arithmetic mean to be $0.79 \mathrm{~nm}$. For this particular membrane, the relative area of micropore defects $a$ was $c a$. $0.13 \%$ yielding a grain size $x$ of $c a$. $1.2 \mu \mathrm{m}$ (see eqn (2)), and consequently a square grain with a surface area of $c a .1 .4 \mu^{2}$. In spite of the great simplicity of the model, the grain size estimated from the permporometry data was in excellent agreement with the grain sizes observed by SEM, i.e. the maximum lengths along the $a$ - and $c$-axis of $c a$. 0.5 and $2 \mu \mathrm{m}$ corresponding to a square grain with a surface area of $1 \mu \mathrm{m}^{2}$. The latter indicates that the micropore defects detected by permporometry in the prepared membrane should mainly be open grain boundaries.

\section{$\mathrm{CO}_{2} / \mathrm{CO}$ separation experiments}

Fig. 4 shows mixed-gas permeances of $\mathrm{CO}_{2}$ and $\mathrm{CO}$ as a function of temperature. High mixed-gas permeances up to $23000 \mathrm{gpu}$ were observed, and the permeance of $\mathrm{CO}_{2}$ was higher than that of $\mathrm{CO}$ in the entire temperature range. With decreasing temperature, the permeances of both $\mathrm{CO}_{2}$ and $\mathrm{CO}$ were decreasing. Bakker et al. ${ }^{37}$ studied temperature dependence of pure-gas permeation of various gases through MFI membranes. It was found that the diffusion of $\mathrm{CO}_{2}$ and $\mathrm{CO}$ in the membranes was activated surface diffusion, for which the diffusivity is increasing with increasing temperature, following an Arrhenius-type expression. The same type of temperature dependence was also found by Kärger et al., ${ }^{38}$ who studied the intracrystalline self-diffusion of $\mathrm{CO}_{2}$ and $\mathrm{CO}$ in MFI zeolite by NMR. Thus, the decrease in permeance with decreasing temperature observed in the present work should emanate from the decrease in the diffusivities. It should be noted, however, that even at the lowest studied temperature of $258 \mathrm{~K}$ the permeance of $\mathrm{CO}_{2}$ was as high as $c a .17000 \mathrm{gpu}$.

Fig. 5 shows $\mathrm{CO}_{2} / \mathrm{CO}$ mixed-gas membrane selectivity as a function of temperature. At the highest studied temperature

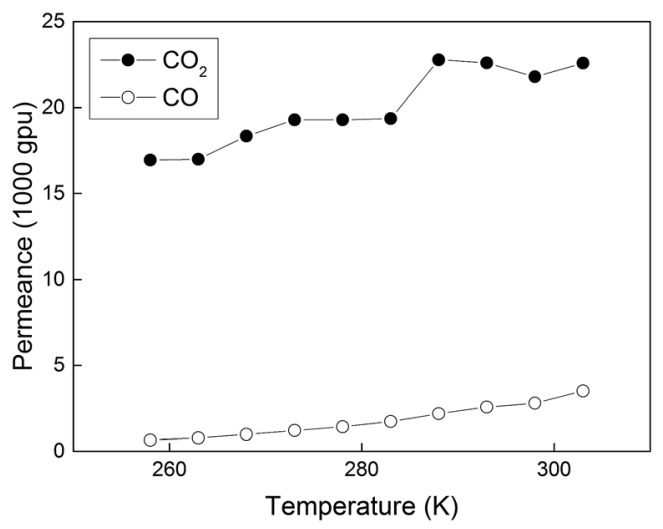

Fig. $4 \mathrm{CO}_{2}$ and $\mathrm{CO}$ permeances measured in the temperature range of $258-303 \mathrm{~K}$ at a feed pressure of 9 bar and a permeate pressure of 1 bar. 
of $303 \mathrm{~K}$, the $\mathrm{CO}_{2} / \mathrm{CO}$ selectivity was $c a .6$, and it was increasing with decreasing temperature, reaching a maximum of 26 at the lowest studied temperature of $258 \mathrm{~K}$. Since the size of both $\mathrm{CO}_{2}$ $(0.33 \mathrm{~nm})$ and $\mathrm{CO}(0.38 \mathrm{~nm})^{37}$ is smaller than the MFI pore size $(0.55 \mathrm{~nm})$, the separation mechanism should rely on the differences in either adsorption or diffusion for the two molecules, and not the molecular sieving. To further elucidate the findings, a modelling work was carried out, and the results will be discussed below.

Table 2 reports the $\mathrm{CO}_{2}$ and $\mathrm{CO}$ fluxes, and the concentration of $\mathrm{CO}_{2}$ and $\mathrm{CO}$ in the permeate stream. The observed $\mathrm{CO}_{2}$ flux was very high, i.e. $320-440 \mathrm{~kg} \mathrm{~m}^{-2} \mathrm{~h}^{-1}$, in the entire temperature range. The high $\mathrm{CO}_{2}$ flux is most likely a result of the very low thickness of the zeolite film, strong $\mathrm{CO}_{2}$ adsorption and high $\mathrm{CO}_{2}$ diffusivity in the zeolite pores, and a relatively high $\mathrm{CO}_{2}$ partial pressure difference of 3.5 bar across the membrane.

In general, performance of supported zeolite membranes is defined by the properties of the active zeolite film and the support. If the thickness of the film is high (e.g. a few microns), the effect of the support on the membrane performance can be neglected since essentially all mass transfer resistance will

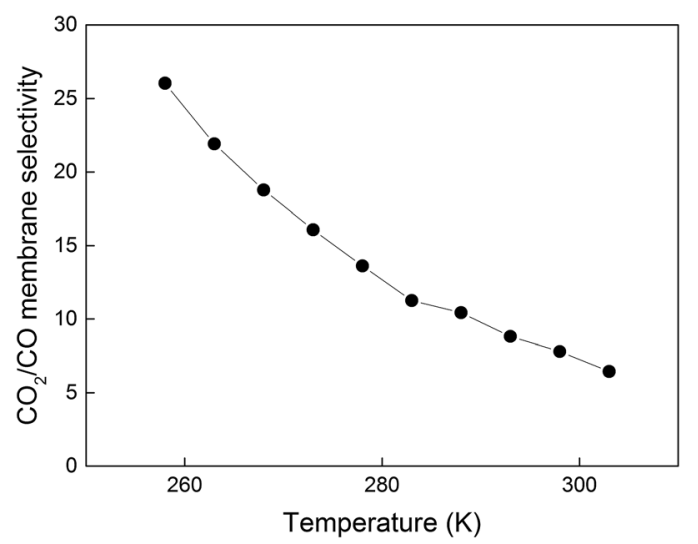

Fig. $5 \mathrm{CO}_{2} / \mathrm{CO}$ membrane selectivity determined in the temperature range of $258-303 \mathrm{~K}$ at a feed pressure of $9 \mathrm{bar}$ and a permeate pressure of 1 bar.

Table $2 \mathrm{CO}_{2}$ and $\mathrm{CO}$ fluxes and permeate concentration observed in the present work

\begin{tabular}{|c|c|c|c|c|}
\hline \multirow[b]{2}{*}{$T(\mathrm{~K})$} & \multicolumn{2}{|c|}{ Flux $\left(\mathrm{kg} \mathrm{h}^{-1} \mathrm{~m}^{-2}\right)$} & \multicolumn{2}{|c|}{$\begin{array}{l}\text { Permeate } \\
\text { concentration }(\mathrm{mol} \%)\end{array}$} \\
\hline & $\mathrm{CO}_{2}$ & $\mathrm{CO}$ & $\mathrm{CO}_{2}$ & $\mathrm{CO}$ \\
\hline 303 & 438 & 51 & 84.75 & 15.63 \\
\hline 298 & 420 & 41 & 86.63 & 13.33 \\
\hline 293 & 434 & 38 & 87.90 & 12.05 \\
\hline 288 & 436 & 32 & 89.12 & 10.40 \\
\hline 283 & 370 & 26 & 90.15 & 9.80 \\
\hline 278 & 367 & 21 & 91.70 & 8.30 \\
\hline 273 & 366 & 18 & 92.80 & 7.15 \\
\hline 268 & 347 & 15 & 93.75 & 6.22 \\
\hline 263 & 321 & 12 & 94.60 & 5.40 \\
\hline 258 & 319 & 10 & 95.35 & 4.60 \\
\hline
\end{tabular}

occur over the zeolite film. In other words, both the overall selectivity and flux of such a membrane will be defined by the properties of the film, which is preferable. However, the high film thickness results in very low flux, ${ }^{7}$ making the membrane impractical. In contrast, if the film thickness is low (i.e. below 1 $\mu \mathrm{m})$, high fluxes, sufficient for a practical application, can be achieved, but the membrane performance may be influenced by the support, as its contribution to the overall mass transfer becomes significant. Roughly speaking, the lower the film thickness, the stronger the support may influence the membrane performance. The effect of the support can also be enhanced if the separated components are small, highly permeable molecules, such as $\mathrm{CO}_{2}$ and $\mathrm{CO}$, as their transport through the film will be even faster. Since the support is normally non-selective or sometimes adversely selective, its contribution to the mass transfer will reduce the separation performance of the membrane. Hence, the effect of the support on the performance of high-flux membranes should be taken into account. In our previous works, ${ }^{21-23}$ we showed that the pressure drop over the support adversely affected the performance of our high-flux membranes for liquid separation of alcohols and water, and gas separation of helium and nitrogen at cryogenic temperature. It is therefore important to study the effect of the support on $\mathrm{CO}_{2} / \mathrm{CO}$ separation reported in the present work. In addition, high-flux membranes may suffer from concentration polarisation on the feed side, reducing the driving force over the film, and therefore selectivity and flux. ${ }^{23}$ In the present work, we have studied the effects of these two phenomena for three different temperatures, viz. 303, 278 and $258 \mathrm{~K}$. The selected points represent high, medium and low flux, respectively. Table 3 shows the results of the evaluation. The relative pressure drop over the support, $\Delta P$, (i.e. pressure drop over the support/pressure drop over the whole composite membrane) was estimated to be $33 \%, 27 \%$ and $21 \%$ at 303,278 and $258 \mathrm{~K}$, respectively. These values are consistent with our previous findings for high-flux MFI zeolite membranes, ${ }^{21-23}$ indicating that the support adversely affected the performance of the membrane. Most of the resistance was found to be in the thin top layer of the support having $100 \mathrm{~nm}$ pores. Therefore, in order to improve the membrane separation performance, the negative effect of the support should be eliminated or at least minimised. One feasible way of minimising this effect would be to reduce the thickness of the top layer from 30 to, e.g. 5-10 $\mu \mathrm{m} .{ }^{24}$ The concentration polarisation index was determined to be $0.83,0.87$ and 0.90 at 303,278 and $258 \mathrm{~K}$, indicating that concentration polarisation reduced the performance of the

Table 3 Relative pressure drop over the support, concentration polarisation index (CPI), permselectivity, and adsorption and diffusional selectivity for the zeolite film estimated for three different temperatures

\begin{tabular}{llllll}
\hline$T(\mathrm{~K})$ & $\Delta P(\%)$ & CPI & $\alpha_{\text {perm,film }}$ & $\alpha_{\text {ads }}$ & $\alpha_{\text {diff }}$ \\
\hline 303 & 33 & 0.83 & 15 & 18 & 0.82 \\
278 & 27 & 0.87 & 24 & 30 & 0.83 \\
258 & 21 & 0.90 & 41 & 46 & 0.89
\end{tabular}


membrane, especially at the higher temperatures, where the flux was higher. In order to minimise the concentration polarisation effect and improve the membrane performance, higher feed flow rates would be required. Additionally, turbulence generating internals in the membrane cell could be used to improve the mass transfer on the feed side. It is also worth noting that if the film thickness were even lower, the negative effect of the support and concentration polarisation on the separation performance would be even higher, and it would thus be even more important to minimise these effects.

The permselectivities for the zeolite film after correcting for concentration polarisation and pressure drop over the support, $\alpha_{\text {perm,film, were } c a .15,24}$ and 41 at 303, 278 and $258 \mathrm{~K}$, respectively. These values differ from the overall selectivities, $c a$. 6, 14 and 26, measured at the same temperatures (see Fig. 5). It is therefore evident that the membrane selectivity was significantly reduced by concentration polarisation and pressure drop over the support.

To better understand the experimental findings, we estimated the adsorption selectivity on the feed side of the membrane using the IAST, after removing the effect of the support and concentration polarisation, see Table 3. The $\mathrm{CO}_{2} / \mathrm{CO}$ adsorption $\alpha_{\text {ads }}$ selectivity was increasing with decreasing temperature. This is expected because the heat of adsorption of $\mathrm{CO}_{2}\left(-24.1 \mathrm{~kJ} \mathrm{~mol}^{-1}\right)$ is more negative than that of $\mathrm{CO}\left(-17.9 \mathrm{~kJ} \mathrm{~mol}^{-1}\right)$ due to the high quadrupole moment and polarisability of the $\mathrm{CO}_{2}$ molecule as compared to $\mathrm{CO}^{32}$ This also shows that the adsorption of $\mathrm{CO}_{2}$ is stronger than the adsorption of CO. Moreover, the estimated adsorption selectivities were very similar to the permselectivities. The latter fact indicates that the membrane selectivity to $\mathrm{CO}_{2}$ should mainly be ascribed to the stronger adsorption of $\mathrm{CO}_{2}$ in the zeolite film. It should also be noted that the adsorption selectivity can probably be increased by increasing the polarity of the zeolite, ${ }^{39}$ i.e. by decreasing the $\mathrm{Si} / \mathrm{Al}$ ratio, resulting in even higher membrane selectivity to $\mathrm{CO}_{2}$. Further, the permselectivity for zeolite membrane may be expressed as the product of the adsorption and diffusional selectivities:

$$
\alpha_{\text {perm }}=\alpha_{\text {ads }} \times \alpha_{\text {diff }} .
$$

The diffusional selectivities may therefore be retrieved from the experimental data shown in Table 3. The diffusional selectivity only varies marginally, from 0.82 at the highest temperature to 0.89 at the lowest temperature. Only a few reports exists on transport of CO through MFI membranes, however Bakker et $a{ }^{37}$ have determined pure-gas diffusivities and activation energies of diffusion of $\mathrm{CO}_{2}$ and $\mathrm{CO}$ in silicalite- 1 from pure-gas membrane permeation data. For $\mathrm{CO}_{2}$ and $\mathrm{CO}$, they reported pure-gas diffusivities of $0.7 \times 10^{-8}$ and $0.9 \times 10^{-8} \mathrm{~m}^{2} \mathrm{~s}^{-1}$ and activation energies of diffusion of 9.6 and $7.1 \mathrm{~kJ} \mathrm{~mol}^{-1}$, respectively. Noticeably, the ratio of the pure-gas diffusivities $\left(D_{\mathrm{CO}_{2}} / D_{\mathrm{CO}}\right)$ yields 0.78 , which is strikingly close to the diffusional selectivity of $c a .0 .82$ that we obtain in the present work at the higher temperatures. As the activation energy of diffusion for $\mathrm{CO}_{2}$ is larger than that for $\mathrm{CO}$, the diffusivity of $\mathrm{CO}_{2}$ should decrease faster than that of $\mathrm{CO}$ with decreasing temperature. Consequently, the ratio of pure-gas diffusivities should also decrease with decreasing temperature, e.g. by $19 \%$ for a temperature decrease from 299 to $248 \mathrm{~K}$. However, our diffusion selectivity was slightly increasing with decreasing temperature, from ca. 0.82 to 0.89 . We ascribe this to increased diffusional coupling (correlation effects) at reduced temperatures. ${ }^{39}$ As the adsorbed loading of $\mathrm{CO}_{2}$ increases, it becomes more effective in slowing down the diffusion of CO (the faster diffusing species), thereby leading to a slight increase in the diffusional selectivity with decreasing temperature. It is also worth noting that since the kinetic diameter of $\mathrm{CO}(0.38 \mathrm{~nm})$ is larger than that of $\mathrm{CO}_{2}(0.33 \mathrm{~nm})$, the overall $\mathrm{CO}_{2} / \mathrm{CO}$ selectivity can probably be increased further by using a smaller-pore zeolite, e.g. CHA zeolite, due to the additional molecular sieving effect favouring the permeation of $\mathrm{CO}_{2}$. It would thus be interesting to develop high-flux CHA zeolite membranes for this separation.

To conclude, the adsorption selectivity was shown to be the dominating factor for the permselectivity observed in this work. In addition, at the high adsorbed loadings obtained at the lower temperatures, diffusional correlation effects also favour the overall $\mathrm{CO}_{2} / \mathrm{CO}$ selectivity, by keeping the diffusional selectivity up (closer to unity).

\section{Conclusions}

Sub-micron $b$-oriented high-flux MFI zeolite membranes were prepared and carefully characterised by permporometry and SEM. By comparing the permporometry and SEM data, the micropore defects detected in the membranes by permporometry were found to be open grain boundaries. The membranes were then evaluated for $\mathrm{CO}_{2} / \mathrm{CO}$ separation at a temperature ranging from 258 to $303 \mathrm{~K}$, a feed pressure of 9 bar and a permeate pressure of 1 bar. The membranes were $\mathrm{CO}_{2}$-selective in the entire temperature range. The highest $\mathrm{CO}_{2} / \mathrm{CO}$ selectivity of 26 was observed at the lowest studied temperature of $258 \mathrm{~K}$. The selectivity of the membrane to $\mathrm{CO}_{2}$ was attributed to the stronger $\mathrm{CO}_{2}$ adsorption, which was supported by a mathematical model based on IAST. The adsorption selectivity, and hence the overall $\mathrm{CO}_{2}$ selectivity can probably be increased further by increasing the polarity of the zeolite. It was also found that diffusional coupling (correlation effects) at high adsorbed loadings resulted in a slight increase of the diffusional selectivity, keeping it closer to unity. In addition, the model indicated that the separation performance of the membrane was reduced by the pressure drop across the support and concentration polarisation on the feed side. Hence, in order to improve the separation performance, these effects should be minimised by, for instance, reducing the thickness of the support and increasing the feed flow rates. Without these effects, a $\mathrm{CO}_{2} / \mathrm{CO}$ selectivity of 41 would be achieved at the lowest studied temperature of $258 \mathrm{~K}$.

\section{Acknowledgements}

Bio4Energy is gratefully acknowledged for financially supporting this work. 


\section{Notes and references}

1 C. Higman and M. v. d. Burgt, Gasification, Gulf Professional Pub./Elsevier Science, Amsterdam, Boston, 2nd edn, 2008.

2 X. Y. Chen, H. Vinh-Thang, A. A. Ramirez, D. Rodrigue and S. Kaliaguine, RSC Adv., 2015, 5, 24399-24448.

3 S. D. Kenarsari, D. Yang, G. Jiang, S. Zhang, J. Wang, A. G. Russell, Q. Wei and M. Fan, RSC Adv., 2013, 3, 2273922773.

4 D. Korelskiy, P. Ye, S. Fouladvand, S. Karimi, E. Sjöberg and J. Hedlund, J. Mater. Chem. A, 2015, 3, 12500-12506.

5 H. Lin, Z. He, Z. Sun, J. Vu, A. Ng, M. Mohammed, J. Kniep, T. C. Merkel, T. Wu and R. C. Lambrecht, J. Membr. Sci., 2014, 457, 149-161.

6 R. W. Baker and B. T. Low, Macromolecules, 2014, 47, 69997013.

7 M. Pera-Titus, Chem. Rev., 2013, 114, 1413-1492.

8 J. Caro and M. Noack, Microporous Mesoporous Mater., 2008, 115, 215-233.

9 E. Sjöberg, L. Sandström, O. G. W. Öhrman and J. Hedlund, J. Membr. Sci., 2013, 443, 131-137.

10 K. V. Agrawal, B. Topuz, T. C. T. Pham, T. H. Nguyen, N. Sauer, N. Rangnekar, H. Zhang, K. Narasimharao, S. N. Basahel, L. F. Francis, C. W. Macosko, S. Al-Thabaiti, M. Tsapatsis and K. B. Yoon, Adv. Mater., 2015, 27, 32433249.

11 J. Caro, M. Noack and E. Stefan, in Advances in Nanoporous Materials, Elsevier, 2010, vol. 1, pp. 1-96.

12 International Zeolite Association (IZA), http://www.izaonline.org/.

13 L. Sandström, E. Sjöberg and J. Hedlund, J. Membr. Sci., 2011, 380, 232-240.

14 Z. P. Lai, G. Bonilla, I. Diaz, J. G. Nery, K. Sujaoti, M. A. Amat, E. Kokkoli, O. Terasaki, R. W. Thompson, M. Tsapatsis and D. G. Vlachos, Science, 2003, 300, 456-460.

15 P. D. Kolokathis, E. Pantatosaki, C.-A. Gatsiou, H. Jobic, G. K. Papadopoulos and D. N. Theodorou, Mol. Simul., 2014, 40, 80-100.

16 J. Kärger, J. Phys. Chem., 1991, 95, 5558-5560.

17 Z. Lai and M. Tsapatsis, Ind. Eng. Chem. Res., 2004, 43, 30003007.

18 M. Zhou, D. Korelskiy, P. Ye, M. Grahn and J. Hedlund, Angew. Chem., Int. Ed., 2014, 53, 3492-3495.
19 J. Hedlund, D. Korelskiy, L. Sandström and J. Lindmark, J. Membr. Sci., 2009, 345, 276-287.

20 D. Korelskiy, M. Grahn, J. Mouzon and J. Hedlund, J. Membr. Sci., 2012, 417-418, 183-192.

21 D. Korelskiy, T. Leppäjärvi, H. Zhou, M. Grahn, J. Tanskanen and J. Hedlund, J. Membr. Sci., 2013, 427, 381-389.

22 L. Yu, D. Korelskiy, M. Grahn and J. Hedlund, Sep. Purif. Technol., 2015, 153, 138-145.

23 P. Ye, M. Grahn, D. Korelskiy and J. Hedlund, AIChE J., 2016, 62, 2833-2842.

24 M. Grahn and J. Hedlund, J. Membr. Sci., 2014, 471, 328-337.

25 I. Perdana, B. W. Tyoso, I. M. Bendiyasa, Rochmadi, S. K. Wirawan and D. Creaser, Chem. Eng. Res. Des., 2009, 87, 1438-1447.

26 F. T. de Bruijn, L. Sun, Z. Olujic, P. J. Jansens and F. Kapteijn, J. Membr. Sci., 2003, 223, 141-156.

27 F. Jareman, J. Hedlund, D. Creaser and J. Sterte, J. Membr. Sci., 2004, 236, 81-89.

28 S. Thomas, R. Schäfer, J. Caro and A. Seidel-Morgenstern, Catal. Today, 2001, 67, 205-216.

29 R. W. Johnson, The handbook of fluid dynamics, CRC Press, Boca Raton, Fla, 1998.

30 A. L. Myers and J. M. Prausnitz, AIChE J., 1965, 11, 121-127. 31 L. Ohlin, P. Bazin, F. Thibault-Starzyk, J. Hedlund and M. Grahn, J. Phys. Chem. C, 2013, 117, 16972-16982.

32 S. K. Wirawan, M. Petersson and D. Creaser, ASEAN Journal of Chemical Engineering, 2008, 8, 9-19.

33 R. Krishna and J. M. van Baten, J. Membr. Sci., 2011, 383, 289-300.

34 R. Krishna, Microporous Mesoporous Mater., 2014, 185, 3050.

35 G. Zeng, C. Chen, D. Li, B. Hou and Y. Sun, CrystEngComm, 2013, 15, 3521-3524.

36 J. Hedlund, F. Jareman, A. J. Bons and M. Anthonis, J. Membr. Sci., 2003, 222, 163-179.

37 W. J. W. Bakker, L. J. P. Van Den Broeke, F. Kapteijn and J. A. Moulijn, AIChE J., 1997, 43, 2203-2214.

38 J. Kärger, H. Pfeifer, F. Stallmach, N. N. Feoktistova and S. P. Zhdanov, Zeolites, 1993, 13, 50-55.

39 R. Krishna and J. M. van Baten, J. Membr. Sci., 2010, 360, 323-333. 